Карпунина Евгения Константиновна, Моисеев Сергей Сергеевич, Лисова Екатерина Валерьевна, Бейлина Анна Феликсовна

\title{
БЕЗОПАСНОСТЬ ПРЕВЫШЕ ВСЕГО: ОБ ЭКОНОМИЧЕСКИХ РИСКАХ И БУДУЩИХ УГРОЗАХ РАЗВИТИЯ ЦИФРОВЫХ ТЕХНОЛОГИЙ
}

Обцество на современном этапе характеризуется устойчивыми тенденциями в развитии цифровых технологий и высоким уровнем информатизации. Под их влиянием формируются новые условия хозяйствования, которые, в свою очередь, определяют целый ряд изменений в жизнедеятельности всех субъектов экономических отночений. Исследованию эффектов иифровизации, которые возникают в процессе вхождения стран мира в цифровое пространство и формирования цифровых экономик, посвящена данная статья. Все эффекты цифровизачии авторами условно разделены на две подгруппь с точки зрения их воздействия на экономическую безопасность хозяйственной системы: положительные и отрицательные. Проанализированы экономические, технологические и сочиальные эффекты цицфрового развития; предложен концепт взаимовлияния циифровой экономики, институциональных изменений и экономической безопасности, а также определен характер их взаимосвязей. Определено, что риски и угрозы экономической безопасности, оказывающие отрицательное воздействие на экономическую систему, способны не только ограничивать ее развитие, но и нивелировать положительные эффекты цифровизации. Обоснована необходимость детальной разработки методов и инструментов обеспечения экономической безопасности на всех уровнях хозяйствования на основе институичинального строительства.

Ключевые слова: цифровое развитие, экономическая безопасность, риски, угрозы, информационные технологии, институциональные изменения.

\section{Evgeniya Karpunina, Sergey Moiseev, Ekaterina Lisova, Anna Beilina SAFETY FIRST: ABOUT ECONOMIC RISKS AND FUTURE THREATS FOR THE DEVELOPMENT OF DIGITAL TECHNOLOGIES}

Modern development of society is inextricably linked with digital technologies and high level of informatization. Under their influence, new economic conditions are formed, which, in turn, determine a number of changes in the life of all subjects of economic relations. This article shows the effects of digitalization in the process of entering the digital space of the world and the formation of digital economies. All the effects of digitalization depending on their impact on the economic security of the state, the authors are conditionally divided into positive and negative, as well as analyzed the economic, technological and social effects of digital development. The concept of mutual influence of digital economy, institutional changes and economic security is offered, and also character of their interrelations is defined. It is determined that risks and threats to economic security can limit the development of the economic system of the state and neutralize the positive effects of digitalization. The necessity of detailed development of methods and tools for ensuring economic security at all levels of management on the basis of institution-building is substantiated.

Key words: digital development, economic security, risks, threats, information technologies, institutional changes.

Bведение / Introduction. Переход к цифровому развитию сопровождается принципиально новыми изменениями в системе экономических отношений на всех уровнях хозяйствования. Некоторые ученые называют современный этап «цифровым цунами», поглощающим все на своем пути и расширяюшимся в пространстве и времени. Действительно, в развитых странах мира 
наблюдается значительный рост доли цифровой экономики в ВВП, а по прогнозным данным компании Gartner к 2025 г., в процесс цифровых преобразований будут вовлечены все сферы хозяйственных систем большинства стран мира [1].

Цифровая экономика формирует условия для разработки и создания новых товаров и услуг, возникновения новых бизнес-моделей, применения цифровых систем управления и логистики. В этих новых условиях происходит общение и удовлетворяются потребности, в них живет и развивается современный человек. Цифры статистики фиксируют масштабность цифрового развития: в 2019 г. в мире количество пользователей социальных сетей составило 3,5 млрд [2], за 2019 г. расходы в сфере электронной коммерции выросли на $14 \%$ по сравнению с аналогичным периодом 2018 г., аудитория Е-commerce в мировом масштабе на сегодняшний момент оценивается в размере 2,8 млрд человек, автоматизировано около 29 \% мирового производства [3]. И это далеко не все показатели стремительного развития цифровой экономики.

Однако цифровая экономика имеет не только ощутимые преимущества, она содержит в себе новые нераспознанные риски и угрозы, которые следует идентифицировать и минимизировать. В условиях цифровой экономики экономическая безопасность приобретает все большее значение, поскольку движение реальных активов становится опосредованным цифровыми носителями и каналами, что, в свою очередь, трансформирует суть производственных и социально-экономических отношений и вызывает институциональные изменения. Поэтому следует изучить положительные и отрицательные эффекты цифровизации сквозь призму институционального строительства и обеспечения экономической безопасности.

Maтериалы и методы / Materials and methods. Затронутая нами тематика является научным продолжением исследования трех взаимосвязанных экономических категорий: «цифровая экономика», «экономическая безопасность» и «институциональные изменения».

Введенный Д. Тапскоттом термин «цифровая экономика» и распространенный благодаря научным изысканиям Н. Негропонте в настоящее время получил широкое распространение в мире, в том числе за счет его практического внедрения в деловое пространство компаний Deloitte, IBM $[4,5]$.

Цифровая экономика с позиций экономической науки может быть представлена как определенный вид экономических отношений, возникающих в процессе производства, распределения, обмена или потребления, которые приобретают технологический характер благодаря использованию информационно-коммуникационных и интернет-технологий, способствующих созданию виртуальной среды, дополняющей реальность [6].

Оценивая масштабы цифровизации, исследователи приходят к выводу, что цифровую экономику можно рассматривать как развивающийся быстрыми темпами сегмент хозяйственной системы, в котором традиционные экономические связи и модели управления бизнес-процессами заменяются и дополняются новыми электронными технологиями производства, обмена и потребления.

Технико-технологическое, цифровое и социально-экономическое развитие общества генерирует новые и неизведанные угрозы и риски [7]. Поэтому вопросы обеспечения экономической безопасности становятся более острыми и жизненно важными, требующими пристального изучения с научных позиций.

Само понятие «безопасность» отождествляется учеными с отсутствием риска, связанного с возможностью нанесения ущерба [8], когда под воздействием совокупности внешних и внутренних факторов не происходит ухудшения параметров экономической системы и возможно ее дальнейшее нормальное функционирование и развитие.

Методология экономической безопасности позволяет идентифицировать риски с различиями в их допустимых уровнях в зависимости от управляемости и прогнозируемости, а также возможных последствий их наступления. Это позволяет рассматривать категорию «экономическая безопасность» как управляемый риск для тех субъектов, которые принимают решения. 
Экономические исследования указывают на первопричины возникновения рисков и угроз экономической безопасности, которые кроются в неразвитости институциональных основ общества, дисбалансе формальных и неформальных институтов, их низкой эффективности. При этом в условиях интенсивного развития информационных систем и технологических решений неразвитые институты могут стать существенным фактором сдерживания темпов цифрового развития и создать условия для возникновения новых рисков экономической безопасности [9].

Pсзульmamы и обсуждение / Results and discussion. Концепт нашего исследования представлен на рисунке.

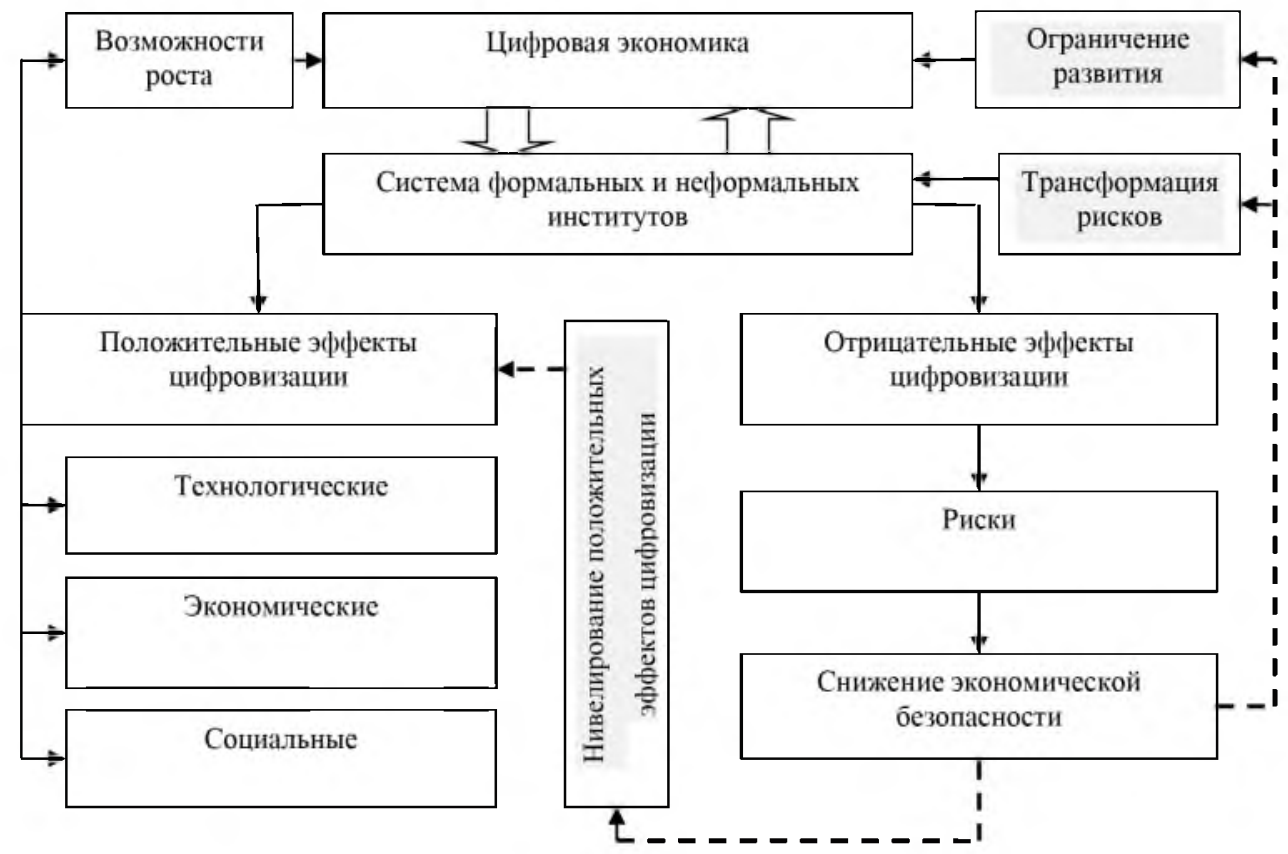

Рис. Концепт взаимовлияния цифровой экономики, институциональных изменений и экономической безопасности

Раскроем выделенные взаимосвязи.

Основу цифровой экономики как новой системы экономических отношений составляют инструменты цифровизации хозяйственной деятельности, информационно-коммуникационные сервисы и технологии, сквозные цифровые инструменты, технологии физической и дополненной реальности, сети Р2P, а также виртуальные механизмы финансовой сферы [10].

Действие указанных инструментов и технологий влияет на традиционные экономические циклы, изменяя последовательность и характер протекания производственных процессов и формируя условия для создания добавочной стоимости через генерацию цифровых экономических благ.

Новые цифровые данные и технологии приобретают все большее значение в сравнении с традиционными видами ресурсов, поскольку они обладают специфическими свойствами [11]: они являются неисчерпаемым ресурсом, не истощаюшимся в процессе использования, способны к тиражированию и распространению; имеют ресурсосберегающие свойства, т. е. способствуют сокращению потребления других ресурсов и формированию ресурсосберегающих и экологически чистых технологий и производств; не приводят к нарушению экологической обстановки; требуют создания универсальных средств производства для развития информационных и цифровых технологий [12]. Многие развитые страны используют явные преимущества цифровых технологий, 
расширяя собственное цифровое пространство и достигая цифрового лидерства в мире. К таким странам следует отнести США, которые (по оценкам Accenture Strategy) обладают крупнейшей в мире цифровой экономикой: инвестиции в развитие цифровых технологий составляют около $33 \%$ ВВП страны; 43 \% рабочей силы США и $26 \%$ совокупного капитала поддерживают деятельность, непосредственно связанную с цифровыми технологиями [13].

Цифровая экономика, как и любой другой тип экономических отношений, базируется на системе формальных и неформальных институтов, которые позволяют принимать технологические решения и выстраивать правила «игры» в новых условиях хозяйствования.

Институциональная теория доказывает, что институты способны оперативно реагировать на любые изменения в системе общественных отношений. Могут также формироваться и новые институты цифрового общества, если происходят системные изменения, требующие преобразований. Так, Д. Норт указал на то, что новые институты возникают в том случае, если общество чувствует потребность в увеличении доходов, однако существующая институциональная система оказывается не способной это обеспечить [9].

Любое институциональное изменение накладывает на каждого участника отношений новые ограничения [10]. Например, А. Аузан обращает внимание на новую проблематику институциональной среды и новые возникающие ограничения в условиях цифровизации [14]:

1) отношение к монополистическим эффектам платформ и иерархий: неэффективность борьбы регулятора с установлением монопольной власти платформ, необходимость ее переориентации на устранение возникающих провалов рынка.

2) изменение правил регулирования цифровых компаний в направлении замены лицензий на регулирование ex post либо саморегулирование;

3) вследствие негативного влияния системы государственной стандартизации на количество патентов обусловливается необходимость построения новой системы стандартизации с учетом мнений независимых игроков на рынке и саморегулирующихся организаций.

В свою очередь, изменение ограничений вызывает трансформацию приоритетов и пересмотр ценности осуществления той или иной деятельности. Например, в обычной модели контрактов Уильямсона - Макнейла выделены классические (сделки), неоклассические (кооперация с посредником) и отношенческие контракты (фирмы). При этом характер активов выступает главным фактором выбора типа контрактов. Наряду с этим в условиях цифровизации возникают новые виды контрактов, такие как: контракт жизненного цикла продукта на основе sharing, smart-контракты с исключением арбитра, контракты глобализированного аутсорсинга для “самозанятых» [14]. Именно поэтому приоритеты хозяйствующих субъектов будут смещаться в сторону заключения новых видов контрактов и роста спроса на новые виды защиты контрактов (например, защита интеллектуальной собственности в связи с цифровым пиратством, защита личной информации).

Таким образом, в условиях становления цифровой экономики адекватность и адаптивность формальных и неформальных институтов будет определять возникновение положительных либо отрицательных эффектов цифровизации.

Положительные эффекты цифровизации можно условно разделить на технологические, экономические и социальные [15].

Например, компания Gartner в качестве примера положительного технологического эффекта цифровизации приводит возникновение новой модели цифрового бизнеса, которая благодаря использованию информационных технологий способна масштабироваться в глобальных масштабах и охватывать индивидов, хозяйствующих субъъектов и предметы их взаимодействия (товары и услуги) через эффективное персональное обслуживание [1].

К положительным экономическим эффектам цифровизации исследователи относят [16]: расширение торговых рынков и операций; рост производительности труда путем сокращения издержек в различных сферах экономики; развитие конкуренции; увеличение количества рабочих 
мест в смежных отраслях; повышение качества услуг. Таким образом, можно утверждать, что развитие цифровой экономики при наличии благоприятной институциональной среды стимулирует экономический рост и создает условия для ускорения его темпов.

Инструменты, которыми оперирует цифровая экономика, позволяют компаниям гибко реагировать на изменение рыночной конъюнктуры, качественнее и быстрее удовлетворять возникающие потребности потребителей. Так, развитие систем электронных платежей способствует многократному ускорению движения финансовых потоков, является источником стимулирования международного товарообмена. Традиционные компании переходят в формат онлайн-работы, а также все чаще применяют инструменты электронной торговли, тем самым обеспечивая ускорение экономического развития.

Очевидны и положительные социальные эффекты цифровизации: повышение инклюзивности и снижение уровня бедности; повышение доступности и рост качества медицинского обслуживания; снижение стоимости и повышение доступности массового образования; улучшение экологической ситуации; повышение доступности финансовых сервисов; сокращение уровня преступности; сокращение рабочего времени и увеличение времени досуга работников (работники в 10 наиболее конкурентоспособных экономиках GCI 4.0 работают в среднем на 361 час меньше в год (в неделю на 8 часов меньше), чем в 10 странах с самым низким рейтингом, для которых существуют данные о рабочем времени (соответствует среднегодовому количеству часов, отработанных занятыми лицами)) [17].

Каковы же отрицательные эффекты цифровизации и что может послужить причиной для возникновения новых угроз и рисков экономической безопасности?

Действительно, смысл цифровой трансформации - в радикальном снижении уровня трансакционных издержек и изменении их структуры [14]. Именно этот факт обеспечивает успех многих цифровых компаний и проектов (от компаний в секторе sharing economy до частных блокчейн-цепей). Это связано со значительным снижением затрат на сбор и обработку информации [18]. Однако кардинальное снижение трансакционных издержек способ́ствует расширению вариантов обмена и вызывает появление новых дискретных институциональных альтернатив. В результате этого формируется «эффект наложения»: одновременное нарастание возможностей и появление конфликтности развития [14]

Таким образом, запускается рост издержек каждой группы субъектов вследствие избыточной институциональной нагрузки, также возникает регулятивный арбитраж, т. е. регулирование схожих видов экономической деятельности с разной степенью интенсивности. Указанные закономерности приводят к перетоку бизнес-структур в сферы экономической деятельности с более низкой регулятивной нагрузкой [10]. Например, такая ситуация может возникнуть в условиях институциональной незрелости на рынке кредитования между банковскими структурами и микрокредитными организациями. Это вызывает сокращение масштабов институционализированного рынка, падение платежеспособного спроса. снижение объема выручки, массовый уход с рынка (игроков) (с неисполненными обязательствами), а также усиление мер надзора и контроля со стороны регулятора (эффект общего усиления регулятивной нагрузки). Возникновение регулятивного арбитража. в свою очередь, напрямую сказывается на потребителе, ослабляет его защищенность и заставляет его пересматривать приоритеты рисков и методы защиты и управления ими.

Цифровая экономика порождает новые угрозы и риски экономической безопасности для всех участников экономических отношений [19]. Так, одним из крупнейших отрицательных эффектов цифровизации может стать интенсивное развитие нового вида преступности - киберпреступности, экономический ущерб от которого имеет значительную динамику роста [20]. Согласно статистике 2017 года, в США ежегодно происходит более 130 крупномасштабных целевых нарушений, и это число растет на $27 \%$ в год. $31 \%$ организаций подверглись кибератакам на 
операционную технологическую инфраструктуру. 100000 групп по меньшей мере в 150 странах и более 400000 машин были заражены вирусом Wannacry в 2017 г., общая стоимость от ущерба составила около \$4 млрд. Атаки, связанные с криптоджекингом, увеличились на $8500 \%$ в 2017 г. Ежедневно блокируется около 24000 вредоносных мобильных приложений [3]. Данный факт, безусловно, является вызовом для систем обеспечения экономической безопасности на всех уровнях хозяйствования.

Человек, его капитал и навыки, а также способность к продуцированию цифровых технологий с позиций экономической безопасности являются пограничными категориями. С одной стороны, развитие человеческого капитала «в ногу со временем» и «на опережение» является неотъемлемым детерминантом развития цифровой экономики. Именно человеческий капитал в условиях цифровой экономики приобретает первостепенное значение среди всех факторов производства, объединяет все другие ресурсы и становится генератором создания новых высокотехнологичных благ и услуг. Таким образом, демонстрируется незаменимость человека в технологическом процессе и безусловный положительный эффект цифровизации, благодаря которому человек должен непрерывно совершенствоваться.

С другой стороны, цифровизация «разворачивает» свои явные преимущества не в пользу человека. Например, изменения рынка труда и высвобождение трудовых ресурсов могут стать реальной угрозой безопасности человека, требующей пересмотра его экономических функций и социальных ценностей [6].

Тем не менее трансформация рынка труда вследствие структурных изменений в хозяйственной системе, вызванных внедрением современных цифровых технологий, неизбежна. Например, по данным Международного экономического форума WEF, около 29 \% мирового производства уже автоматизировано, и для сравнения к 2022 г. доля машин и алгоритмов в рабочем времени составит, по их прогнозу, уже $42 \%$, а к 2025 г. - 52 \%. То есть роботы уже в ближайшее время практически могут заменить половину человеческого труда. При этом многие эксперты единодушны в том, что только четверть рабочих мест может быть автоматизирована более чем на $70 \%$ - это области обработки данных, которые автоматизированы в настоящее время приблизительно на $47 \%$, а к 2022 г. будет подвержено автоматизации уже $62 \%$. С ростом безработицы происходит снижение производительности и сокращение совокупных доходов общества [6], обострение проблем социально-экономического неравенства. Это означает возможный подрыв экономической безопасности государства. В этом случае возникнет дисбаланс между институциональными сдвигами и экономическими основами общества, которые должны формироваться под влиянием институциональных изменений. Это требует от государства создания действенного компенсаторного механизма при замещении человека техникой и получения безусловного базового дохода.

Заключение /Conclusion. Рассмотренные риски и угрозы экономической безопасности, оказывающие отрицательное воздействие на экономическую систему, способны не только ограничивать ее развитие. «Мутация рисков», которая может происходить вследствие углубления и расширения цифровой экономики, способна нивелировать положительные эффекты цифровизации.

В связи с этим требуется использование научного подхода к определению инструментария обеспечения экономической безопасности на всех уровнях хозяйственной системы. В основу данного подхода должно быть заложено понимание безопасности как “управляемого риска», которого можно избежать, предотвратить, репрессировать либо элиминировать его убытки. Путем реализации грамотной государственной политики и создания институциональных условий для цифровизации возможно добиться перевода рисков, приводящих к разрушительным последствиям, из одной категории в другую, тем самым предотвратить негативные проявления. Такой подход к управлению рисками экономической безопасности в условиях цифровизации позволит целенаправленно воздействовать на неформальные институты, которые будут встраиваться в формальные и обеспечивать базовые принципы экономической безопасности. 


\section{ЛИТЕРАТУРА И ИНТЕРНЕТ-РЕСУРСЫ}

1. Top 10 Strategic Technology Trends for 2019 (Gartner Inc.). - URL: https://www.gartner.com/ smarterwithgartner/gartner-top-10-strategic-technology-trends-for-2019 (дата обращения: 10.06.2019). Текст : электронный.

2. Сергеева, У. Вся статистика Интернета на 2019 год - в мире и в России (Web-canape) / У. Сергеeва. - URL: https://www.callcentrehelper.com/consumers-expect-brand-communications-136541.htm (дата обращения 01.06. 2019). - Текст : электронный.

3. Digital Market Outlook (Statista). - URL: https://www.statista.com/outlook/digital-markets (дата обращения 18.05.2019). - Текст : электронный.

4. Tapscott, D. The Digital Economy: Promise and Peril In The Age of Networked Intelligence / D. Tapscott. McGraw-Hill, 1995. - 342 p. - Текст : непосредственный.

5. Negroponte, N. Being Digital. Knopf. / N. Negroponte. - New York, 1995. 256 p. - Текст : непосредственный.

6. Стрелкова, И. А. Цифровая экономика: новые возможности и угрозы для развития мировой экономики / И. А. Стрелкова // Экономика. Налоги. Право. - 2018. - № 2. - С. 18-26. - Текст : непосредственный.

7. Karpunina, E. Growth potential and economic security threats in terms of digital economy ecosystem / E. Karpunina, E. Yurina, I. Kuznetsov, A. Dubovitski // The 33nd International Business Information Management Association (IBIMA). 10-11 April 2019. - Granada, Spain, 2019. - P. 2669-2679. - Текст : непосредственный.

8. Российская энциклопедия по охране труда: в 3 т. / рук. проекта М. Ю. Зурабов; отв. ред. А. Л. Сафонов. - 2-е изд., перераб. и доп. - Москва : НЦ ЭНАС, 2007. - Текст : непосредственный.

9. Норт Д. Институты, институциональные изменения и функционирование экономики / Д. Норт; пер. с англ. А. Н. Нестеренко; предисл. и науч. Ред. Б. З. Мильнера. - Москва : Фонд экономической книги «Начала», 1997. - 190 с. - Текст : непосредственный

10. Горулев, Д. А. Экономическая безопасность в цифровой экономике / Д. А. Горулев // Технико-технологические проблемы сервиса. - 2018. - № 1(43). - с. 77-84. - Текст : непосредственный.

11. Юсупов, Р. М. Информатизация как фактор инновационного роста экономики / Р. М. Юсупов // Экономика и управление. -2009 . - № 10. - С. 5-10. - Текст : непосредственный.

12. Попов, Е. Компаративный анализ стратегических аспектов развития цифровой экономики / Е. Попов, К. Семячков // Вестник пермского университета. Серия «Экономика». - 2018. - Том 13. - № 1. c. 19-36. - Текст : непосредственный.

13. Knickrehm, M. Digital Disruption: The Growth Multiplier, Accenture / M. Knickrehm, B. Berthon, P. Daugherty. - URL: https://www.accenture.com/_acnmedia/PDF-4/Accenture-Strategy-DigitalDisruptionGrowth-Multiplier.pdf (дата обращения: 23.07.2017). - Текст : электронный.

14. Аузан, А. Цифровая экономика как экономика сверхнизких трансакционных издержек (набор гипотез) / А. Аузан. - URL: https://www.econ.msu.ru/sys/raw.php?o=51299\&p=attachment (дата обращения: 15.05.2019). - Текст : электронный.

15. A future that works: automation, employment and productivity (McKinsey Global Institute. 2017). - URL: https://docviewer.yandex.ru/view/316254058/ (дата обращения 10.08.2019). - Текст : электронный.

16. Международный банк реконструкции и развития, Всемирный Банк. Доклад о мировом развитии. 2016. Цифровые дивиденды. - URL: http://www.worldbank.org/ru/events/2016/02/01/central-asialaunchwdr-2016 (дата обращения: 18.12.2017). - Текст : электронный.

17. Feenstra, R. The Next Generation of the Penn World Table / R. Feenstra, R. Inklaar, M. Timmer // American Economic Review. - 2015. - № 105(10). - P. 3150-3182. - Текст : непосредственный.

18. Loebbecke, C. Reflections on Societal and Business Model Transformation arising from Digitization and Big Data Analytics: A Research. Agenda / C. Loebbecke, A. Picot // Journal of Strategic Information Systems (JSIS). - 2015. - № 24(3). - P. 149-157. - Текст : непосредственный.

19. Мамаева, Л. Н. Характерные проблемы информационной безопасности в современной экономике / Л. Н. Мамаева // Информационная безопасность регионов. - 2016. - № 1 (22). - С. 21-24.

20. Удалов, Д. В. Угрозы и вызовы цифровой экономики / Д. В. Удалов // Экономическая безопасность и качество. - 2018. - № 1 (30). - С. 12-18. - Текст : непосредственный. 


\section{REFERENCES AND INTERNET RESOURCES}

1. Top 10 Strategic Technology Trends for 2019 (Gartner Inc.) [Elektronnyj resurs]. - URL: https://www. gartner.com/smarterwithgartner/gartner-top-10-strategic-technology-trends-for-2019/ [data obrashcheniya: 10.06.2019].

2. Sergeeva, U. Vsya statistika Interneta na 2019 god - v mire i v Rossii (Web-canape). [Elektronnyj resurs] / a USergeev.. - URL: https://www.callcentrehelper.com/consumers-expect-brand-communications-136541. $\mathrm{htm}$ [data obrashcheniya 01.06. 2019].

3. Digital Market Outlook (Statista). [Elektronnyj resurs]. - URL: https://www.statista.com/outlook/digitalmarkets[data obrashcheniya 18.05.2019].

4. Tapscott, D. The Digital Economy: Promise and Peril In The Age of Networked Intelligence / D. Tapscott. McGraw-Hill, 1995. - 342 p.

5. Negroponte, N. Being Digital. Knopf. / N. Negroponte. - New York, 1995. - 256 p.

6. Strelkova, I. A. Cifrovaya ekonomika: novye vozmozhnosti i ugrozy dlya razvitiya mirovoj ekonomiki / I. A. Strelkova // Ekonomika. Nalogi. Pravo. - 2018. - № 2. - S. 18-26.

7. Karpunina, E. Growth potential and economic security threats in terms of digital economy ecosystem / E. Karpunina, E. Yurina, I. Kuznetsov, A. Dubovitski // The 33nd International Business Information Management Association (IBIMA), - Granada, Spain, 10-11 April - 2019. - S. 2669-2679.

8. Rossijskaya enciklopediya po ohrane truda: v 3 t. / ruk. proekta M. YU. Zurabov; otv. red. A. L. Safonov. 2-e izd., pererab. i dop. - Moskva : NC ENAS, 2007.

9. Nort D. Instituty, institucional'nye izmeneniya i funkcionirovanie ekonomiki / D. Nort; per. s angl. A. N. Nesterenko; predisl. i nauch. red. B. Z. Mil'nera. - Moskva : Fond ekonomicheskoj knigi «Nachala», 1997. $-190 \mathrm{~s}$.

10. Gorulev, D. A. Ekonomicheskaya bezopasnost' v cifrovoj ekonomike / D. A. Gorulev // Tekhnikotekhnologicheskie problemy servisa. - 2018. - № 1(43). - S. 77-84.

11. Yusupov, R. M. Informatizaciya kak faktor innovacionnogo rosta ekonomiki / R. M. Yusupov // Ekonomika i upravlenie. -2009 . - № 10. - S. 5-10.

12. Popov, E. Komparativnyj analiz strategicheskih aspektov razvitiya cifrovoj ekonomiki / E. Popov, K. Semyachkov // Vestnik Permskogo universiteta. Seriya «Ekonomika». - 2018. - T. 13. - № 1. - S. 19-36.

13. Knickrehm, M. Digital Disruption: The Growth Multiplier, Accenture [Elektronnyj resurs] / M. Knickrehm, B. Berthon, P. Daugherty. - URL: https://www.accenture.com/_acnmedia/PDF-4/Accenture-StrategyDigital-DisruptionGrowth-Multiplier.pdf [data obrashcheniya: 23.07.2017].

14. Auzan, A. Cifrovaya ekonomika kak ekonomika sverhnizkih transakcionnyh izderzhek (nabor gipotez) / A. Auzan [Elektronnyj resurs]. - URL: https://www.econ.msu.ru/sys/raw.php?o=51299\&p=attachment [data obrashcheniya: 15.05.2019].

15. A future that works: automation, employment and productivity (McKinsey Global Institute. 2017) [Elektronnyj resurs]. - URL: https://docviewer.yandex.ru/view/316254058/ [data obrashcheniya 10.08.2019].

16. Mezhdunarodnyj bank rekonstrukcii i razvitiya, Vsemirnyj Bank. Doklad o mirovom razvitii. 2016. Cifrovye dividendy [Elektronnyj resurs]. - URL: http://www.worldbank.org/ru/events/2016/02/01/centralasia-launchwdr-2016 [data obrashcheniya: 18.12.2017].

17. Feenstra, R. The Next Generation of the Penn World Table / R. Feenstra, R. Inklaar, M. Timmer // American Economic Review. - 2015. - № 105 (10). - P. 3150-3182.

18. Loebbecke, C. Reflections on Societal and Business Model Transformation arising from Digitization and Big Data Analytics: A Research. Agenda / C. Loebbecke, A. Picot // Journal of Strategic Information Systems (JSIS). - 2015. - № 24 (3). - P. 149-157.

19. Mamaeva, L. N. Harakternye problemy informacionnoj bezopasnosti v sovremennoj ekonomike / L. N. Mamaeva // Informacionnaya bezopasnost' regionov. - 2016. - № 1 (22). - S. 21-24.

20. Udalov, D. V. Ugrozy i vyzovy cifrovoj ekonomiki / D. V. Udalov // Ekonomicheskaya bezopasnost' i kachestvo. - 2018. - № 1 (30). - S. 12-18. 


\section{СВЕДЕНИЯ ОБ АВТОРАХ}

Карпунина Евгения Константиновна, доктор экономических наук, профессор, профессор кафедры «Политическая экономия и современные бизнес-процессы» ФГБОУ ВО «Тамбовский государственный университет имени Г.Р. Державина», г. Тамбов. E-mail egenkak@mail.ru

Моисеев Сергей Сергеевич, кандидат педагогических наук, доцент кафедры «Политическая экономия и современные бизнес-процессы» ФГБОУ ВО «Тамбовский государственный университет имени Г. Р. Державина», г. Тамбов. E-mail econom $@$ tsutmb.ru

Лисова Екатерина Валерьевна, кандидат социологических наук, доцент кафедры «Экономика, менеджмент и маркетинг» ФГОБУ ВО «Финансовый университет при правительстве Российской Федерации» (филиал в г. Липецк), г. Липецк. E-mail lisovaekaterina78@gmail.com

Бейлина Анна Феликсовна, кандидат экономических наук, доцент кафедры философии, экономики и социально-гуманитарных дисциплин ФГБОУ ВО «Воронежский государственный педагогический университет», г. Воронеж. E-mail abejlina $@$ yandex.ru

\section{INFORMATION ABOUT AUTHORS}

Evgeniya Karpunina, Doctor of Economic Sciences, Professor, Professor of the Department «Political economy and modern business processes», Tambov State University named after G. R. Derzhavin, Tambov. E-mail egenkak@mail.ru

Sergey Moiseev, Ph-D, associate Professor of the Department «Political economy and modern business processes», Tambov State University named after G. R. Derzhavin, Tambov. E-mail econom $@$ tsutmb.ru

Ekaterina Lisova, Ph-D, associate Professor of the Department «Economics, management and marketing» Financial University under the government of the Russian Federation (branch in Lipetsk). E-mail lisovaekaterina78@) gmail.com

Anna Beilina, Ph-D, associate Professor of the Department of Philosophy, Economics and social and humanitarian disciplines, Voronezh state pedagogical University, Voronezh. E-mail abejlina $a$ yandex.ru 